\title{
A Novel Technique for Controllable Fabrication of Multilayer Copper/Brass Block
}

\author{
Jiansheng Li ${ }^{1,2,3,4,+}+{ }^{\circ}$, Zhongchen Zhou ${ }^{5,+}$, Tong Liu ${ }^{1,3, *}$, Yu Zhao ${ }^{1,3}$, Yan Lu ${ }^{4}$, Ming Chen ${ }^{1,3}$, \\ Xiaozhen Wang ${ }^{1}$, Gang Wang ${ }^{1,3}$ iD and Qingzhong Mao ${ }^{5, *}$ \\ 1 School of Materials Science and Engineering, Anhui Polytechnic University, Wuhu 241000, China; \\ drlijiansheng@163.com (J.L.); zhaoyu@ahpu.edu.cn (Y.Z.); chenming@ahpu.edu.cn (M.C.); \\ 15862713652@163.com (X.W.); gangwang@ahpu.edu.cn (G.W.) \\ 2 School of Chemistry and Materials Science, Anhui Normal University, Wuhu 241000, China \\ 3 Anhui Key Laboratory of High-Performance Non-Ferrous Metal Materials, Anhui Polytechnic University, \\ Wuhu 241000, China \\ 4 Anhui Xinke New Materials Stock Co., Ltd., Wuhu 241006, China; luyan9876luyan@126.com \\ 5 Nano and Heterogeneous Materials Center, School of Materials Science and Engineering, \\ Nanjing University of Science and Technology, Nanjing 210094, China; zhouzhongchen@njust.edu.cn \\ * Correspondence: liutong@ahpu.edu.cn (T.L.); 216116000150@njust.edu.cn (Q.M.) \\ + These authors contributed equally to this work.
}

Citation: Li, J.; Zhou, Z.; Liu, T.; Zhao, Y.; Lu, Y.; Chen, M.; Wang, X.; Wang, G.; Mao, Q. A Novel Technique for Controllable Fabrication of Multilayer Copper/Brass Block. Coatings 2021, 11, 1416. https:// doi.org/10.3390/coatings11111416

Academic Editor: Tomasz

Chmielewski

Received: 26 October 2021

Accepted: 18 November 2021

Published: 20 November 2021

Publisher's Note: MDPI stays neutral with regard to jurisdictional claims in published maps and institutional affiliations.

Copyright: (c) 2021 by the authors. Licensee MDPI, Basel, Switzerland. This article is an open access article distributed under the terms and conditions of the Creative Commons Attribution (CC BY) license (https:// creativecommons.org/licenses/by/ $4.0 /)$.

\begin{abstract}
Fabricating a dissimilar-metal block with micro/nano-multilayered structures is usually used by engineers and scientists because of their excellent mechanical properties. In the current work, multilayered copper/brass blocks were effectively fabricated by a synthetical DWFR technique, which includes the processes of diffusion welding, forging and rolling. Diffusion welding was used as the first operation to metallurgically bond the copper and brass sheets, with a Zn diffusion transition layer (thickness of $\sim 100 \mu \mathrm{m}$ ), which can guarantee the bonding strength of copper/brass interfaces during the subsequent forging and rolling processes. After diffusion welding, the original copper/brass blocks were required to be forged, with its total thickness reduced to $\sim 10 \mathrm{~mm}$. This can further restrain the delamination of copper and brass layers during the final rolling process. Rolling was utilized as the ideal operation that can precisely tune the thickness of copper/brass laminate. This novel DWFR technique can easily tune the multilayered copper/brass blocks with controllable layer thickness (from $\sim 250$ to $\sim 800 \mathrm{~nm}$ ). The copper/brass interfaces were well-bonded, and the utilization efficiency of raw materials was very high $(>95 \%)$.
\end{abstract}

Keywords: diffusion welding; forging; rolling; copper/brass block; layer thickness

\section{Introduction}

Multilayered dissimilar-metal blocks have always attracted attention due to their superior mechanical properties, such as high strength, good ductility and excellent impact toughness [1-5]. As investigated in many previous studies, the multilayered dissimilar-metal blocks can be prepared using the techniques of physical vapour deposition (PVD) [6,7], high pressure torsion (HPT) [8], accumulative rolling bonding (ARB) [9,10] and diffusion welding + rolling (DWR) $[2,4,11]$, etc. Generally, all of the above-mentioned techniques have their weaknesses. The PVD technique can precisely fabricate the multilayered dissimilar-metal blocks with nanolayers, although its low production efficiency may limit its application for the preparation of large-size products. Similarly, it was also difficult for HPT technique to fabricate materials large enough for industrial applications because of the small size of raw materials required for HPT. The shape of the raw material of HPT is usually a disk and the diameter of the disk is determined by the dimension of the extrusion die, which is usually less than $20 \mathrm{~mm}$ [12]. The ARB technique was believed to be useful and highly efficient for the preparation of a multilayered dissimilar-metal block with a large size sample and a controllable micro/nano-thickness of each layer. However, some 
concerns have arisen related to the low utilization efficiency of raw materials and low deformation bonding strength, which often result from the inevitable micro-cracks, oxygen and contaminants during repeated ARB operations [9,10,13]. Recently, Li et al. [2,4] indicated that multilayered dissimilar-metal blocks can be constructed using the DWR technique. The DWR-processed samples were of large sizes, well-bonded transition interfaces and demonstrated a high utilization efficiency of raw materials $(\sim 100 \%)$. Unfortunately, it was difficult to decrease the layer thickness to the value of $<100 \mu \mathrm{m}$, which was ascribed to the delamination of the multilayered block with a larger original thickness during the rolling operation. As reported by Ma et al. [14] and Huang et al. [3], a higher strength and ductility were more likely to be obtained for multilayered blocks with layer thicknesses of several micrometers or nanometers. This was also reported for other materials, for which preparing nanostructures can usually achieve superior physical and chemical properties [15-20]. Hence, efforts should be made to further decrease the final layer thicknesses for dissimilar-metal blocks for DWR technique. There is also an urgent need to identify an appropriate processing technique that can fabricate multilayered dissimilar-metal blocks with the large production sizes, well-bonded interfaces, a high utilization efficiency of raw materials and a controllable layer thickness of the micro/nanometers.

Copper/brass blocks with micro/nano-multilayered structures are expected to have a high strength, according to previous literatures [3,4], thereby meeting the requirements for the structural components. In addition, pure $\mathrm{Cu}$ and $\mathrm{Cu}$ alloys had good thermal/electrical conductivities [21-24]. Thus, a copper/brass block can be used as a structural material in the field of thermal/electrical conductivity applications.

In this study, a combined processing technique of diffusion welding, forging and rolling (DWFR technique) is reported for the first time. Multilayered copper/brass blocks were effectively fabricated using the DWFR technique. This DWFR technique may provide technical guidance for fabricating other multilayered dissimilar-metal blocks.

\section{Experimental Procedure}

\subsection{Materials and DWFR/ARB Processing}

Commercial brass (Cu-30 wt.\% Zn, ASTM-C26000, Tongling Nonferrous Metals Group Holdings Co., Ltd, Tongling, China) and pure copper (99.9 wt.\% Cu, ASTM-C11000, Tongling Nonferrous Metals Group Holdings Co., Ltd, Tongling, China) sheets were used to fabricate the multilayered copper/brass block. Before the DWFR fabrication process, the copper sheets and brass sheets with an original size of $80 \mathrm{~mm} \times 100 \mathrm{~mm} \times 1 / 0.5 \mathrm{~mm}$ and $80 \mathrm{~mm} \times 100 \mathrm{~mm} \times 0.8 / 0.4 \mathrm{~mm}$ were mechanically polished by $1500 \# \mathrm{SiC}$ paper (the grit size of $\sim 10 \mu \mathrm{m}$ ), and then washed in an acetone solution for $15 \mathrm{~min}$, to achieve the clean surfaces. The fabrication processing procedure that was followed is detailed in Figure 1. It includes the following four steps: (I) 20/50 pieces of copper sheets and 20/50 pieces of brass sheets are alternately stacked with total thickness of $\sim 36$ (40 layers) or $\sim 45 \mathrm{~mm}$ (100 layers); (II) the diffusion welding technique is used to obtain an original multilayered copper/brass block with well-bonded copper/brass interfaces. The static pressure, heating temperature and holding time are $2 \mathrm{MPa}, 920^{\circ} \mathrm{C}$ and $2 \mathrm{~h}$, respectively; (III) after diffusion welding treatment, the origin copper/brass laminate suffers forging deformation with its thickness reduced from $\sim 36 / \sim 45$ to $\sim 10 \mathrm{~mm}$ at room temperature; (IV) synchronous rolling treatment is further utilized to tune the layer thickness of the copper/brass laminate at room temperature. The roll dimension is $\Phi 120 \mathrm{~mm} \times 250 \mathrm{~mm}$, the velocity of roll is $\sim 65 \mathrm{~mm} / \mathrm{s}$, and the thickness reduction is $\sim 0.2 \mathrm{~mm}$ per pass at room temperature. 


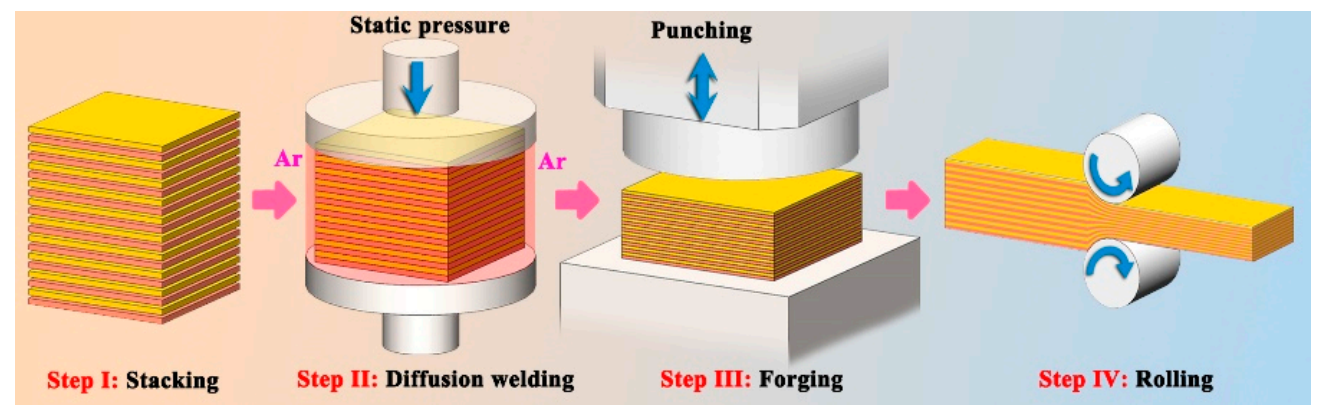

Figure 1. Schematic illustration of the procedure for the DWFR processing.

Before ARB fabrication processing, the copper sheets and brass sheets with the original size of $80 \mathrm{~mm} \times 25 \mathrm{~mm} \times 1 \mathrm{~mm}$ and $80 \mathrm{~mm} \times 25 \mathrm{~mm} \times 0.8 \mathrm{~mm}$ were also mechanically polished by $1500 \#$ SiC paper, and then washed in an acetone solution for $15 \mathrm{~min}$, to achieve the clean surfaces. The roll dimension is $\Phi 120 \mathrm{~mm} \times 250 \mathrm{~mm}$, the velocity of roll is $\sim 65 \mathrm{~mm} / \mathrm{s}$, and the rolling strain is $50 \%$ per pass at room temperature.

\subsection{Calculation of the Utilization Efficiency of Raw Materials}

The utilization efficiency $(\eta)$ of raw materials in the present work were calculated using the following equation:

$$
\eta=1-\left(m_{1}+m_{2}+m_{3}\right) / m_{0}
$$

where the $m_{0}$ was the total mass of as-received copper and brass sheets, $m_{1}, m_{2}$ and $m_{3}$ were the loss masses during the diffusion, forging and rolling processes, usually caused by cutting, cracking and delamination, etc.

\subsection{Characterizations}

An optical microscope (OM, Olympus BX41M, OLYMPUS, Tokyo, Japan) was utilized to characterize the cross-sectional structure of the multilayered copper/brass block. The chemical element distribution and morphologies of the copper/brass interfaces were captured by a field emission scanning electron microscope (SEM, Quant 250 FEG, FEI, Hillsboro, OR, USA) equipped with X-ray energy dispersive spectroscopy (EDS, Oxford, Abingdon-on-Thames, Britain).

\section{Results and Discussion}

The diffusion welding technique is an effectively method that can connect dissimilar metals through the metallurgical bonding of the dissimilar-metal surfaces. The pressure is usually $2 \mathrm{MPa}$ and the high processing temperature is $920{ }^{\circ} \mathrm{C}$. Figure 2 shows the multilayered copper/brass block prepared using a diffusion welding technique with 40 layers. The copper and brass sheets are successfully bonded to form a block. As presented in Figure 3a, both the copper layer and brass layer consist of an equiaxed coarsegrained structure embedded with some $\Sigma 3$ twins. This is a typical annealed structure for pure copper and its alloys $[3,4,25]$. Figure $3 b, c$ indicate that the copper layer and brass layer in the as-diffusion-welded copper/brass block are bonded with a Zn diffusion transition layer (thickness of $\sim 100 \mu \mathrm{m}$ ) while the centers of copper and brass layer still show the original chemical compositions. The diffusion activity of $\mathrm{Zn}$ can improve the bonding strength and impede delamination of the copper/brass interface during the deformation process [4]. Thus, the Zn diffusion transition layer present in the copper/brass block is believed to guarantee the bonding strength during subsequent deformation operations. In order to further decrease the layer thickness and achieve a layer thickness of several micrometers or nanometers, an appropriate deformation technique should be used. In fact, rolling is hardly ever competent. This is attributed to the fact that high shear stress and strain are easily caused by the large thickness of the total copper/brass block during 
the rolling operation $[26,27]$. In the current work, the 11-layered copper/brass block (total thickness of $\sim 10 \mathrm{~mm}$ ) and 18-layered block (total thickness of $\sim 16 \mathrm{~mm}$ ) have been cut from the original 40-layered diffusion-welded block. As displayed in Figure 4, a larger original thickness is more likely to result in the delamination of the copper/brass interfaces during the rolling process, which may indicate that $\sim 10 \mathrm{~mm}$ may approach the critical value of thickness that restrains the delamination of the copper/brass interfaces. In order to obtain a layer thickness of several micrometers or nanometers, the original copper/brass block should firstly, be deformed with the thickness reduced to $\sim 10 \mathrm{~mm}$ using an appropriate deformation operation. As analyzed for the stress state of uniaxial forging deformation, only the vertical punch load is generated by the hammer, which may cause a low shear stress between dissimilar layers and effectively shape metals without cracking. Thus, conventional forging is utilized as the first deformation operation to punch the copper/brass laminate, with the total thickness reduced from $\sim 36$ to $\sim 10 \mathrm{~mm}$.

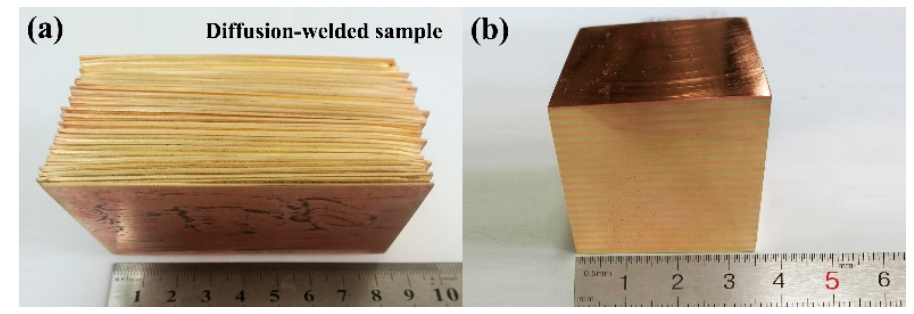

Figure 2. (a) The optical image of the diffusion-welded sample with 40 layers; (b) The optical image of the diffusion-welded sample with the dimension of $35 \mathrm{~mm} \times 35 \mathrm{~mm} \times 36 \mathrm{~mm}$, which is cut from the diffusion-weld sample in (a).

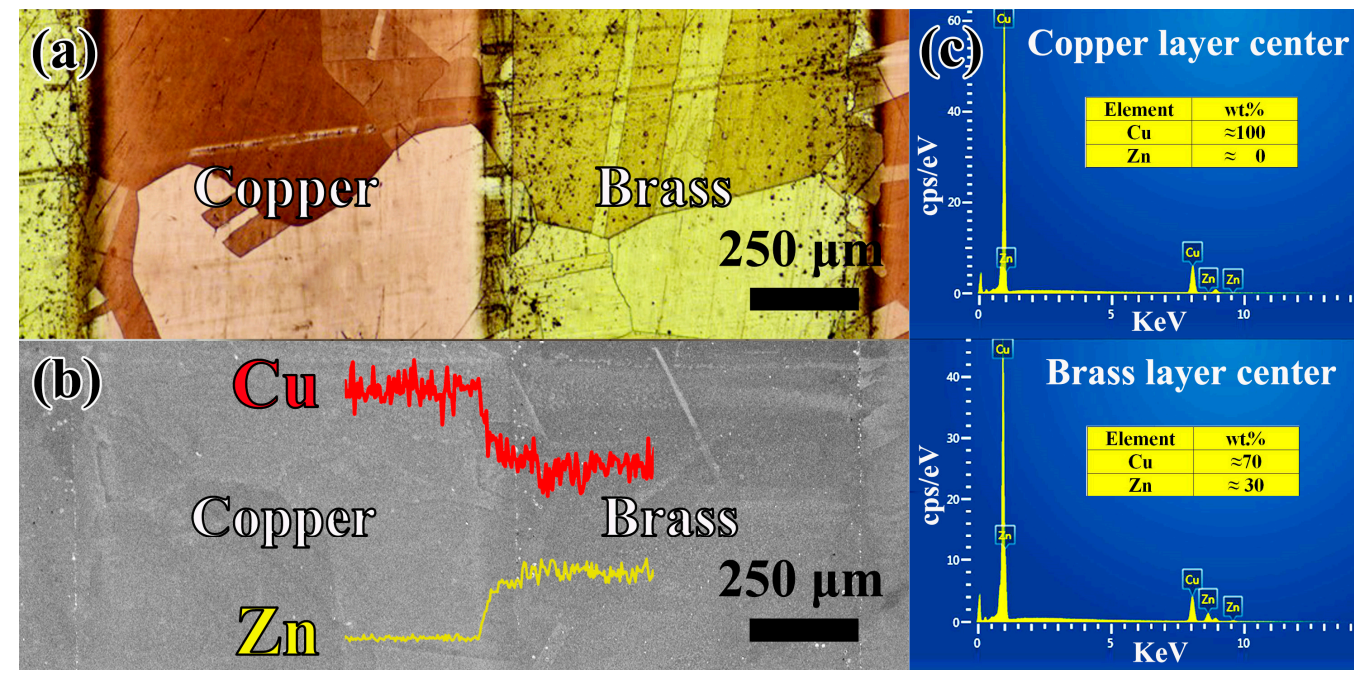

Figure 3. (a) Cross-sectional microstructures of the copper and brass layer after diffusion welding; (b) EDS line maps around copper/brass interface after diffusion welding; (c) EDS results of the copper layer center and brass layer center after diffusion welding.

As presented in Figure 5, no micro-crack or delamination is observed between the copper/brass interfaces for the forged sample, which can guarantee the high utilization efficiency of raw materials. Following the forging operation, rolling is selected as the second deformation operation to tune the thickness of copper/brass laminate because of its higher precision and higher surface flatness $[28,29]$. In the current work, multilayered copper/brass blocks with various layer thicknesses $(250,100,50$ and $5 \mu \mathrm{m})$ are effectively fabricated by our DWFR technique, clearly displayed in Figure 6. It is noted that no macroscopic delamination (well-bonded interfaces) or waste of the deformed copper/brass blocks during rolling operations occurred. The present DWFR technique is superior to the ARB 
technique for processing copper and brass sheets with similar sizes at room temperature, which is confirmed by Figures 6 and 7, illustrating the occurrence of delamination during ARB processing. Some efforts are devoted to further reduce the thickness value of copper and brass layer down to $<1000 \mathrm{~nm}$. Figure 8 exhibits the DWFR-processed sample with an average layer thickness of $\sim 800 \mathrm{~nm}$ and a total thickness of $\sim 80 \mu \mathrm{m}$. We calculated that the utilization efficiency of raw materials for DWFR-processed copper/brass blocks is more than $95 \%$, which is comparable to that of the DWR technique [4]. Although a nano-thickness layer of $<100 \mathrm{~nm}$ is not exhibited in the present work, it is believed that it can be easily obtained by increasing the number of original copper/brass sheets or reducing the final thickness of the rolled sample. In fact, this study provides only a brief overview of the DWRF technique, and the authors will conduct further investigations using different kinds of metals.

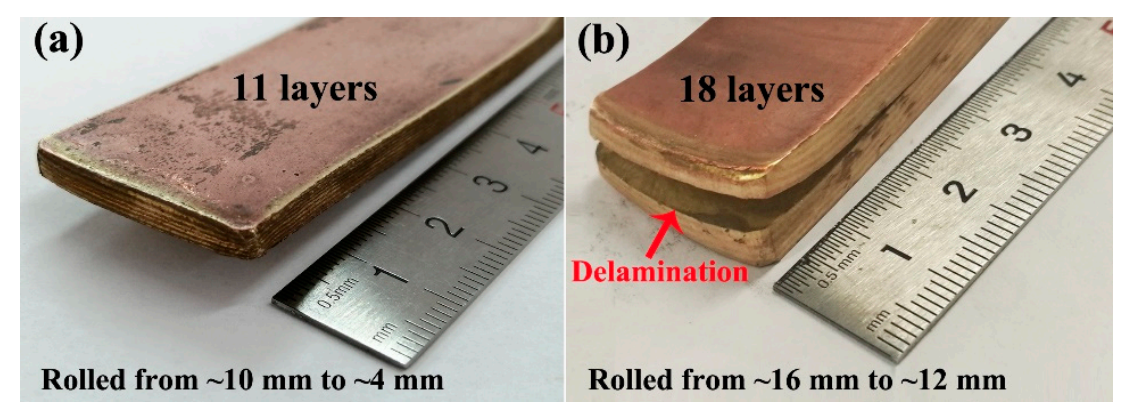

Figure 4. (a) The optical image of the 11-layered diffusion-welded sample with rolling strain of $\sim 60 \%$ (thickness reduced from $\sim 10$ to $\sim 4 \mathrm{~mm}$ ); (b) The optical image of the 18-layered diffusion-welded sample with rolling strain of $\sim 25 \%$ (thickness reduced from $\sim 16$ to $\sim 12 \mathrm{~mm}$ ). It is noted that the mentioned samples are both cut from the original diffusion-welded sample (40-layers).

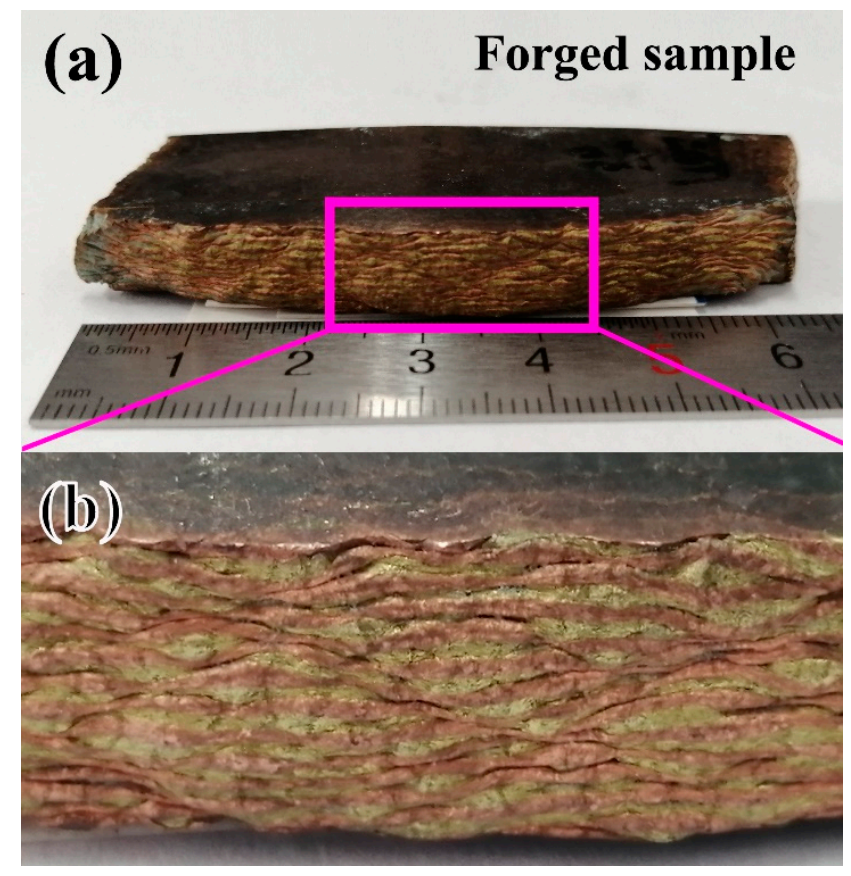

Figure 5. (a) The optical image of the forged sample with 40 layers; (b) The enlarged image of the cross-section of the forged sample. 


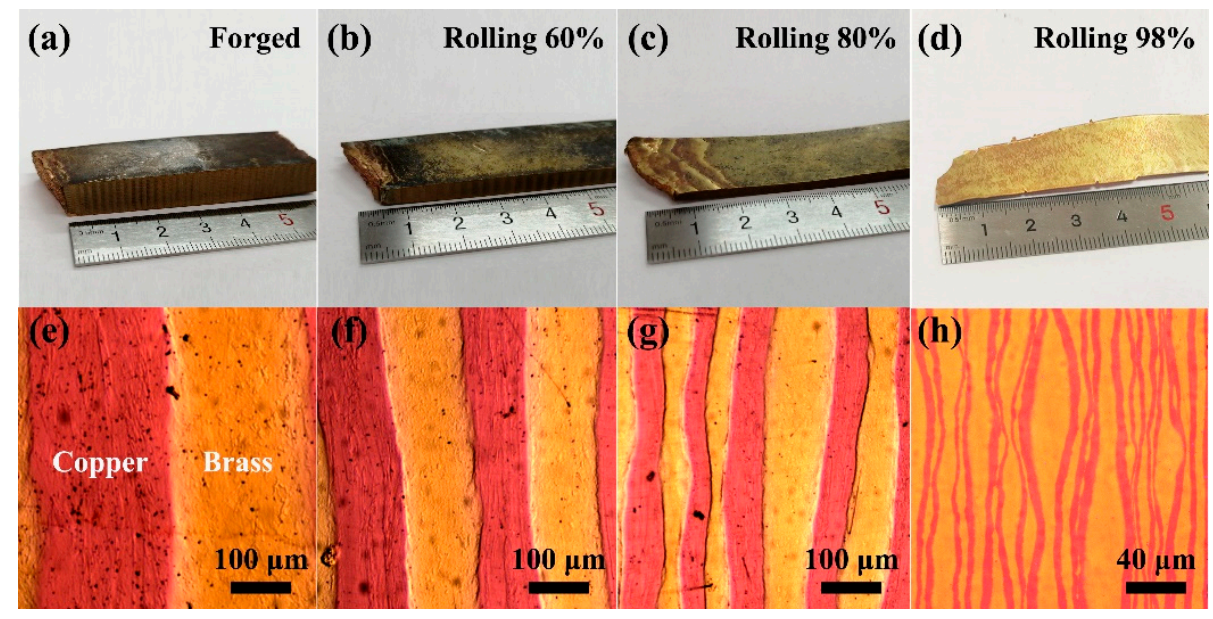

Figure 6. (a-d) are optical images of the forged sample, rolling $60 \%$ sample, rolling $80 \%$ sample, rolling $98 \%$ sample (40 layers), respectively; (e-h) are the corresponding microstructures of cross-sections of the forged sample, rolling $60 \%$ sample, rolling $80 \%$ sample, rolling $98 \%$ sample, respectively.

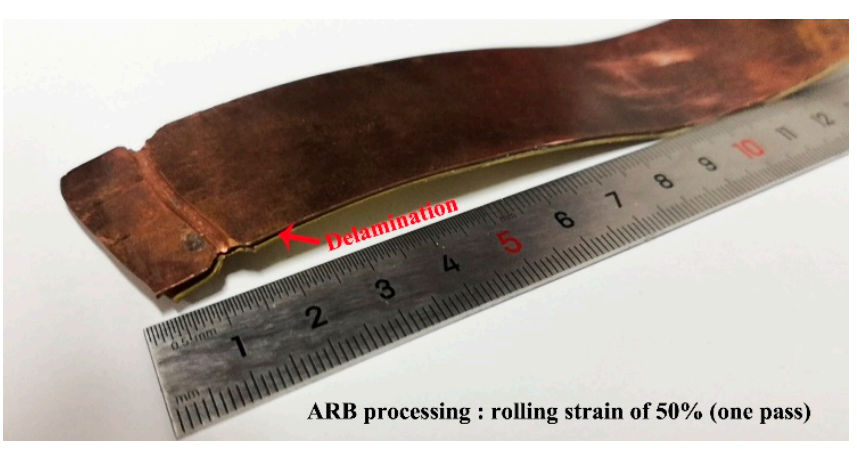

Figure 7. The optical image of the ARB-processed copper/brass block. The original thicknesses of copper sheet and brass sheet are 1 and $0.8 \mathrm{~mm}$, respectively.

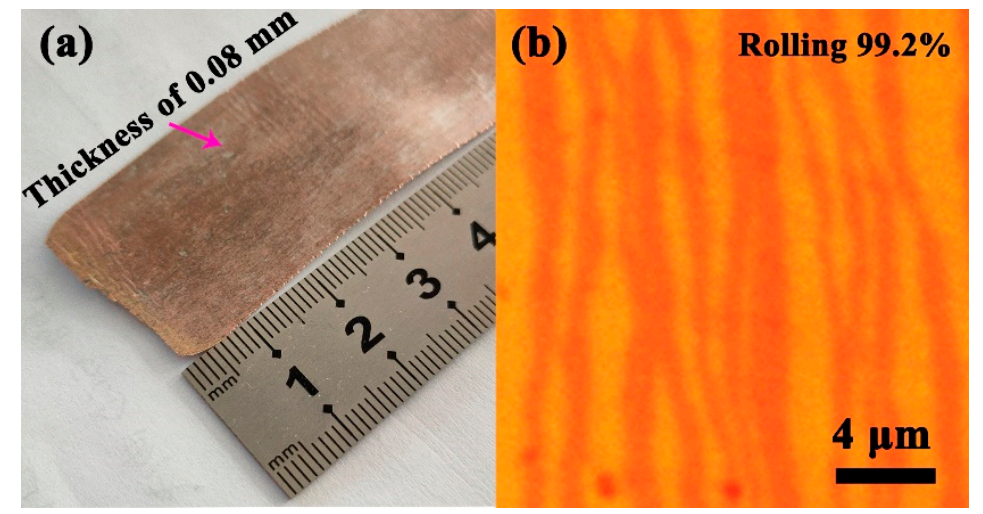

Figure 8. (a) is the optical image of the DWFR-processed sample (100 layers); (b) is the corresponding microstructures of (a).

\section{Conclusions}

In summary, the present work first reported a synthetical DWFR technique, including the process of diffusion welding, forging and rolling, which can effectively achieve the fabrication of multilayered copper/brass blocks. Some conclusions can be drawn, as follows: 
- The DWFR technique can easily tune the multilayered copper/brass block with a controllable layer thickness, from $\sim 250 \mu \mathrm{m}$ to $\sim 800 \mathrm{~nm}$.

- Well-bonded transition interfaces can be obtained via a diffusion welding treatment, which can suppress the delamination between copper and brass layers during severe deformation, caused by forging and rolling operations.

- DWFR and ARB products are of similar sizes, and can meet the size requirements for industrial products.

- The DWFR technique has a high utilization efficiency of raw materials ( $>95 \%)$, which greatly reduces the costs of raw materials.

- This DWFR technique also provides technical guidance for fabricating other multilayered dissimilar-metal blocks.

Author Contributions: Formal analysis, J.L. and X.W.; Investigation, J.L. and Z.Z.; Methodology, Y.Z. and Y.L.; Resources, G.W.; Writing—original draft, J.L. and T.L.; Writing—review \& editing, M.C. and Q.M. All authors have read and agreed to the published version of the manuscript.

Funding: The present work was supported by the National Natural Science Foundation of China (Grant No. 52001001, 52101030) and the Scientific Research Starting Foundation of Anhui Polytechnic University of China (Grant No. 2020YQQ026).

Institutional Review Board Statement: Not applicable.

Informed Consent Statement: Not applicable.

Data Availability Statement: The data presented in this study are available on request from the corresponding authors.

Conflicts of Interest: The authors declare no conflict of interest.

\section{References}

1. Cepeda-Jiménez, C.M.; García-Infanta, J.M.; Pozuelo, M.; Ruano, O.A.; Carreño, F. Impact toughness improvement of highstrength aluminum alloy by intrinsic and extrinsic fracture mechanisms via hot rolling bonding. Scr. Mater. 2009, 61, 407-410. [CrossRef]

2. Qin, W.B.; Mao, Q.Z.; Kang, J.J.; Liu, Y.Y.; Shu, D.F.; She, D.S.; Liu, Y.F.; Li, J.S. Superior impact property and fracture mechanism of a multilayered copper/bronze laminate. Mater. Lett. 2019, 250, 60-63. [CrossRef]

3. Huang, C.X.; Wang, Y.F.; Ma, X.L.; Yin, S.H.; Hoppel, W.; Goken, M.; Wu, X.L.; Gao, H.J.; Zhu, Y.T. Interface affected zone for optimal strength and ductility in heterogeneous laminate. Mater. Today 2018, 21, 713-719. [CrossRef]

4. Li, J.S.; Wang, S.Z.; Mao, Q.Z.; Huang, Z.W.; Li, Y.S. Soft/hard copper/bronze laminates with superior mechanical properties. Mater. Sci. Eng. A 2019, 756, 213-218. [CrossRef]

5. Liu, T.; Gu, C.Y.; Li, J.S.; Zhou, Z.C.; Lu, Y.; Gao, F.; Chen, M.; Mao, Q.Z.; Lu, X.K.; Li, Y.S. Effect of structural orientation on the impact properties of a soft/hard copper/brass laminate. Vacuum 2021, 191, 110388. [CrossRef]

6. Druzhinin, A.V.; Ariosa, D.; Siol, S.; Ott, N.; Straumal, B.B.; Janczak-Rusch, J.; Jeurgens, L.P.H.; Cancellieri, C. Effect of the individual layer thickness on the transformation of $\mathrm{Cu} / \mathrm{W}$ nano-multilayers into nanocomposites. Materialia $2019,7,100400$. [CrossRef]

7. Krella, A.K.; Czyniewski, A.; Gilewicz, A.; Gajowiec, G. Experimental study of the influence of deposition of multilayer $\mathrm{CrN} / \mathrm{CrCN}$ PVD coating on austenitic steel on resistance to cavitation erosion. Coatings 2020, 10, 487. [CrossRef]

8. Ma, X.L.; Huang, C.X.; Xu, W.Z.; Zhou, H.; Wu, X.L.; Zhu, Y.T. Strain hardening and ductility in a coarse-grain/nanostructure laminate material. Scr. Mater. 2015, 103, 57-60. [CrossRef]

9. Lu, C.; Tieu, K.; Wexler, D. Significant enhancement of bond strength in the accumulative roll bonding process using nano-sized $\mathrm{SiO}_{2}$ particles. J. Mater. Process. Technol. 2009, 209, 4830-4834. [CrossRef]

10. Mahdavian, M.M.; Ghalandari, L.; Reihanian, M. Accumulative roll bonding of multilayered Cu/Zn/Al: An evaluation of microstructure and mechanical properties. Mater. Sci. Eng. A 2013, 579, 99-107. [CrossRef]

11. Huang, M.; Xu, C.; Fan, G.H.; Maawad, E.; Gan, W.M.; Geng, L.; Lin, F.X.; Tang, G.Z.; Wu, H.; Du, Y.; et al. Role of layered structure in ductility improvement of layered Ti-Al metal composite. Acta Mater. 2018, 153, 235-249. [CrossRef]

12. Zhilyaev, A.P.; Langdon, T.G. Using high-pressure torsion for metal processing: Fundamentals and applications. Prog. Mater. Sci. 2008, 53, 893-979. [CrossRef]

13. Fard, N.M.N.; Mirzadeh, H.; Rezayat, M.; Cabrera, J.M. Accumulative roll bonding of aluminum/stainless steel sheets. J. Ultrafine Grained Nanostruct. Mater. 2017, 50, 1-5. [CrossRef]

14. Ma, X.L.; Huang, C.X.; Moering, J.; Ruppert, M.; Hoppel, H.W.; Goken, M.; Narayan, J.; Zhu, Y.T. Mechanical properties of copper/bronze laminates: Role of interfaces. Acta Mater. 2016, 116, 43-52. [CrossRef] 
15. Salavati-Niasari, M. Zeolite-encapsulation copper(II) complexes with 14-membered hexaaza macrocycles: Synthesis, characterization and catalytic activity. J. Mol. Catal. A Chem. 2004, 217, 87-92. [CrossRef]

16. Salavati-Niasari, M. Nanoscale microreactor-encapsulation 14-membered nickel(II) hexamethyl tetraaza: Synthesis, characterization and catalytic activity. J. Mol. Catal. A Chem. 2005, 229, 159-164. [CrossRef]

17. Salavati-Niasari, M.; Sobhani, A.; Davar, F. Synthesis of star-shaped PbS nanocrystals using single-source precursor. J. Alloy. Compd. 2010, 507, 77-83. [CrossRef]

18. Salavati-Niasari, M.; Davar, F.; Loghman-Estarki, M.R. Controllable synthesis of thioglycolic acid capped ZnS(Pn) 0.5 nanotubes via simple aqueous solution route at low temperatures and conversion to wurtzite ZnS nanorods via thermal decompose of precursor. J. Alloy. Compd. 2010, 494, 199-204. [CrossRef]

19. Ghanbari, D.; Salavati-Niasari, M.; Sabet, M. Preparation of flower-like magnesium hydroxide nanostructure and its influence on the thermal stability of poly vinyl acetate and poly vinyl alcohol. Compos. Part B 2013, 45, 550-555. [CrossRef]

20. Zinatloo-Ajabshir, S.; Morassaei, M.S.; Salavati-Niasari, M. Eco-friendly synthesis of $\mathrm{Nd}_{2} \mathrm{Sn}_{2} \mathrm{O}_{7}$-based nanostructure materials using grape juice as green fuel as photocatalyst for the degradation of erythrosine. Compos. Part B 2019, 167, 643-653. [CrossRef]

21. Liang, N.N.; Liu, J.Z.; Lin, S.C.; Wang, Y.; Wang, J.T.; Zhao, Y.H.; Zhu, Y.T. A multiscale architectured CuCrZr alloy with high strength, electrical conductivity and thermal stability. J. Alloy. Compd. 2018, 735, 1389-1394. [CrossRef]

22. Mao, Q.Z.; Zhang, Y.S.; Liu, J.Z.; Zhao, Y.H. Breaking material property trade-offs via macrodesign of microstructure. Nano Lett. 2021, 21, 3191-3197. [CrossRef]

23. Mao, Q.Z.; Zhang, Y.S.; Guo, Y.Z.; Zhao, Y.H. Enhanced electrical conductivity and mechanical properties in thermally stable fine-grained copper wire. Commun. Mater. 2021, 2, 46. [CrossRef]

24. Mao, Q.Z.; Chen, X.; Li, J.S.; Zhao, Y.H. Nano-gradient materials prepared by rotary swaging. Nanomaterials 2021, 11, 2223. [CrossRef]

25. Straumal, B.B.; Polyakov, S.A.; Mittemeijer, E.J. Temperature influence on the faceting of $\Sigma 3$ and $\Sigma 9$ grain boundaries in Cu. Acta Mater. 2006, 54, 167-172. [CrossRef]

26. Zhang, T.; Wu, Y.X.; Gong, H.; Zheng, X.Z.; Jiang, S.S. Effects of rolling parameters of snake hot rolling on strain distribution of aluminum alloy. Trans. Nonferr. Met. Soc. China 2014, 24, 2150-2156. [CrossRef]

27. Wang, T.; Liu, W.L.; Liu, Y.M.; Wang, Z.H.; Ignatov, A.V.; Huang, Q.X. Formation mechanism of dynamic multi-neutral points and cross shear zones in corrugated rolling of Cu/Al laminated composite. J. Mater. Process. Technol. 2021, 295, 117157. [CrossRef]

28. Yu, H.L.; Lu, C.; Tieu, A.K.; Li, H.J.; Godbole, A.; Zhang, S.H. Special rolling techniques for improvement of mechanical properties of ultrafine-grained metal sheets: A review. Adv. Eng. Mater. 2016, 18, 754-769. [CrossRef]

29. Tran, D.C.; Tardif, N.; Limam, A. Experimental and numerical modeling of flatness defects in strip cold rolling. Inter. J. Solids Struct. 2015, 69-70, 343-349. [CrossRef] 